\author{
Revista Brasileira de Educação do Campo \\ The Brazilian Scientific Journal of Rural Education \\ ARTIGO/ARTICLE/ARTÍCULO \\ DOI: http://dx.doi.org/10.20873/uft.rbec.e7129
}

\title{
Pedagogia da Alternância em comunidade pomerana de Santa Maria de Jetibá, Espírito Santo, Brasil
}

\author{
Edineia Koeler ${ }^{1}$, Erineu Foerste ${ }^{2}$, Alberto Merler ${ }^{3}$ \\ ${ }^{1}$ Universidade Federal do Espírito Santo - UFES / Europa Universität Viadrina - Frankfurt, Alemanha. Programa de Pós- \\ Graduação em Educação / Viadrina: Faculdade de Ciências da Cultura. Avenida Fernando Ferrari, 514, Goiabeira, Vitória - ES, \\ Brasil / Viadrina: Grosse Scharrnstrasse 59 15230, Frankfurt (ODER), Alemanha. ${ }^{2}$ Universidade Federal do Espírito Santo - \\ UFES. ${ }^{3}$ Universidade de Sassari, Sassari, Itália. \\ Autor para correspondência/Author for correspondence: edikoeler@hotmail.com
}

\begin{abstract}
RESUMO. O artigo analisa aspectos da Pedagogia da Alternância, compreendida na perspectiva de Nosella (1977, 2012), e sua relação com a cultura pomerana. Toma como objeto de estudo a Escola Estadual Emílio Schroeder, situada em Alto Santa Maria, Santa Maria de Jetibá, Espírito Santo, Brasil, para entender como tal comunidade, com presença significativa do povo tradicional pomerano, compreende $\mathrm{o}$ projeto de alternância. Com abordagem qualitativo-descritiva, beneficia-se de narrativas de uma professora-monitora com significativa experiência em Escolas Família Agrícola e, adicionalmente, analisa um conjunto de documentos constituído por 52 fichasquestionários aplicadas em 2011 às famílias dos alunos. O tratamento interpretativo das respostas a quatro itens de tal instrumento permitiu constatar que, decorrida uma década da implantação do regime de alternância na escola, ocorrida em 2001, e não sendo os pais que responderam a tal instrumento os mesmos que lutaram pelo regime de alternância na escola, houve mudanças no significado atribuído pelas famílias e comunidade em geral a esse modelo educacional no contexto social analisado. Destaca-se que as dimensões culturais e identitárias do povo tradicional pomerano podem contribuir para a problematização do projeto escolar; que a iniciativa das comunidades rurais é fundamental para a conquista e permanência de projetos alternativos na educação do campo; que a pouca escolaridade dos pais pode ter reflexos imediatos no trabalho da escola, mas não os impede de buscar qualidade de ensino para os filhos.
\end{abstract}

Palavras-chave: Pedagogia da Alternância, Comunidade Escolar, Cultura Pomerana.

\begin{tabular}{|l|l|l|l|l|l|l|} 
RBEC & Tocantinópolis/Brasil & v. 4 & e7129 & $10.20873 /$ uft.rbec.e7129 & 2019 & ISSN: 2525-4863 \\
\hline
\end{tabular}




\title{
The Pedagogy of Alternation in pomerana community of Santa Maria de Jetibá, Espírito Santo, Brazil
}

\begin{abstract}
The article analyzes aspects of the Alternation Pedagogy, understood from Nosella's perspective (1977, 2012), and its relationship with Pomeranian culture. It takes as its study object the Emílio Schroeder State School, located in Alto Santa Maria, Santa Maria de Jetibá, Espírito Santo, Brazil, to understand how such a community, with a significant presence of the traditional Pomeranian people, comprises the alternation project. With a qualitative-descriptive approach, it benefits from narratives of a teacher-monitor with significant experience in Agricultural Family Schools and, in addition, analyzes a set of documents consisting of 52 questionnaire forms applied in 2011 to student's families. The interpretative treatment of the responses to four items of this instrument showed that, after a decade of the implementation of the alternation regime in school, which occurred in 2001, and it was not the parents who responded to this instrument the same who fought for the alternation regime in the school. There have been changes in the meaning given by families and the wider community to this educational model in the social context analyzed. It is noteworthy that the cultural and identity dimensions of the traditional Pomeranian people can contribute to the problematization of the school project; whereas the initiative of rural communities is fundamental for the conquest and permanence of alternative projects in rural education; that parent's poor education may have immediate repercussions on schoolwork, but it does not prevent them from seeking quality education for their children.
\end{abstract}

Keywords: Pedagogy of Alternation, Scholar Community, Pomeranian Culture. 


\section{La Pedagogía de Alternancia en una comunidad pomerana de Santa Maria de Jetibá, Espírito Santo, Brasil}

RESUMEN. Este artículo analiza aspectos de la Pedagogía de la Alternancia, según la perspectiva de Nosella $(1977,2012)$, y como se relaciona con la cultura pomerania. El objeto de la investigación es la Escuela Estatal Emílio Schroeder, situada en Alto Santa Maria, en Santa Maria de Jetibá, Espírito Santo, Brasil, para comprender cómo una comunidad de este tipo, con una presencia significativa de los pueblos tradicionales de Pomerania, comprende el proyecto de alternancia. Bajo un enfoque cualitativo y descriptivo, el estudio se llevó a cabo a partir de las narraciones de una profesora con experiencia significativa en las Escuelas Familiares Agrícolas y, además, analiza un conjunto de documentos que consisten en 52 encuestas que fueron contestadas por las familias de los estudiantes en 2011. El análisis de las respuestas a los cuatro elementos que componían la investigación, revela que después de 17 años desde la introducción de la alternancia en esta escuela y no siendo los padres los mismos que lo defendieron, hubo cambios en el significado que las familias y la sociedad en general asocian a esta pedagogía. Sobresale las dimensiones culturales y de identidad de los pueblos tradicionales pomeranos que pueden contribuir a la problematización del proyecto escolar; considerando que la iniciativa de las comunidades agrícolas es esencial para la conquista y la permanencia de proyectos alternativos en la educación rural; que la poca escolaridad de los padres puede tener consecuencias inmediatas en el trabajo escolar, pero eso no les detiene en la busca por una educación de calidad para sus hijos.

Palabras clave: Pedagogía de la Alternancia, Comunidad Escolar, Cultura Pomerana. 


\section{Introdução}

O objetivo deste artigo é discutir aspectos da prática da Pedagogia da Alternância na comunidade de Alto Santa Maria, município de Santa Maria de Jetibá, no Estado do Espírito Santo (ES), onde se localiza a Escola Estadual de Ensino Fundamental e Médio (EEEFM) Fazenda Emílio Schroeder, referida ao longo deste texto como Escola Emílio Schroeder. Buscamos evidenciar como as famílias dos alunos, na sua maioria, descendentes de pomeranos, compreendem o modelo de alternância na formação de seus filhos e as possíveis mudanças que ocorrem nessa compreensão ao longo do tempo.

No contexto da região onde foi desenvolvida esta pesquisa, há duas outras instituições de ensino que trabalham com a Pedagogia da Alternância, a saber, a Escola Família Agrícola (EFA) de São João de Garrafão, localizada no distrito de Garrafão, também em Santa Maria de Jetibá, e a EFA São Bento do Chapéu, situada na comunidade homônima, no município de Domingos Martins (ES).

O presente estudo, entretanto, está delimitado à Escola Emílio Schroeder e deu origem à pesquisa de mestrado de um dos autores deste artigo, realizada também em Alto Santa Maria, comunidade em que o investigador atualmente desenvolve sua tese de doutorado. Esta escola cumpre os quesitos do currículo comum estabelecido pela rede estadual de ensino do Espírito Santo, à qual se vincula e no âmbito da qual preconiza um projeto ousado.

Tal projeto começou a ser reivindicado pela comunidade local por volta de 1993, em colaboração com a equipe da escola, e consiste na oferta de um ensino que articula ferramentas da Pedagogia da Alternância e do ensino convencional da rede pública estadual de ensino. Entretanto, somente foi concretizado em 2001. Uma das características dessa filosofia educacional é oportunizar a comunidade escolar a criação de seu próprio currículo, enquanto o Estado esforça-se pela padronização curricular. Esse movimento de forças, portanto, faz a experiência na Escola Emílio Schroeder ser um misto de duas pedagogias que ora se complementam, ora se distanciam.

Partimos do fato de que, diferentemente da EFA Garrafão e da EFA São Bento do Chapéu, que contam com aparato pedagógico necessário ao bom desenvolvimento da Pedagogia da Alternância, a EEEFM Fazenda Emílio Schroeder, por sua vez, apresenta particularidades nesse quesito. Isso porque, ainda hoje, a Secretaria Estadual de Educação do Espírito Santo (SEDU), que 
regula sua atuação, não dispõe de meios para dar o apoio que as pedagogias alternativas requerem. Possivelmente pelo já mencionado intuito de manter o currículo padronizado.

Sobre o binômio "comunidade escolar", destacamos que se trata de um conceito complexo e abrangente, pois envolve todos os segmentos que, de alguma maneira, participam do processo educativo promovido em uma escola (alunos, pais, comunidades e as equipes pedagógica e administrativa da escola). Nesse entendimento, na maioria dos casos em que é usada, a expressão incorpora professores, funcionários, pais e alunos. Contudo, neste trabalho, além desses atores, seu uso tem amplitude maior, pois abarca não apenas os moradores de Alto Santa Maria, como também os das localidades vizinhas, de onde procedem alguns dos estudantes matriculados na Escola Emílio Schroeder.

Em face das especificidades da Pedagogia da Alternância e limitações que ela experimenta para sua plena realização na Escola Emílio Schroeder, o artigo discute como as famílias de seus alunos, parte integrante da comunidade escolar, compreendem esse regime de ensino. Nesse sentido, este texto está assim organizado: em um primeiro momento, discorremos sobre a história da Pedagogia da Alternância no Espírito Santo, por onde ela chega ao Brasil, destacando sua dinâmica de funcionamento, para, em seguida, caracterizar a Escola Emílio Schroeder.

Posteriormente à descrição dos procedimentos metodológicos usado neste estudo, destacamos o relato de experiência de uma professora-monitora de escolas que utilizam a Pedagogia de Alternância, com atuação também na Escola Emílio Schroeder. O relato evidencia que, implantada na sua intregralidade, a filosofia da alternância permite, entre moradores de comunidades rurais e a escola, um encontro em que a tônica é a forte conexão entre ambas, além da não contraposição entre prática e teoria no cultivo da terra e nos modos de ser e viver no campo.

O texto segue caracterizando a comunidade abarcada pela Escola Emílio Schroeder, que envolve não somente, mas, sobretudo, Alto de Santa Maria, comunidade que se destaca pela presença dos descendentes pomeranos, pela prática da agroecologia e efervescentes mobilizações coletivas, inclusive, para a implantação da Pedagogia da Alternância na referida unidade escolar.

Em seguida, apresentamos a análise das fichas usadas por professores da Escola Emílio Schroeder para fazer registros de 
visita às famílias em 2011. A escolha pela análise do material desta data deve-se ao fato de que ele permite observar se a visão dessas famílias sobre o modelo de alternância se diferenciava em relação à visão daquelas famílias que, no início dos anos 1990, se engajaram na luta por uma escola que lançasse um olhar diferente para as especificidades do campo, direito conquistado somente na década seguinte.

Como objeto do interesse de um dos autores deste texto, o sentido que a comunidade de Alto Santa Maria dá à Pedagogia de Alternância continua sendo investigado em pesquisa de doutoramento. Assim, uma nova atualização desses dados está prevista para ser divulgada nos próximos dois anos, quando a adoção da alternância na Escola Emílio Schroeder completará 20 anos, sendo possível comparar, em cada década, a ressignificação desse regime por parte dos atores que constituem a comunidade escolar.

\section{Pedagogia da Alternância}

A princípio, será discutido o histórico da Pedagogia da Alternância e algumas de suas características, o que se faz com base em Nosella (1977, 2012), para quem tal modelo educacional é comumente compreendido como um sistema de ensino que tem por princípio a formação integral do ser humano, desde a concepção da vida em comunidade, passando pela valorização do espaço e do homem do campo até chegar à educação formal, instituída pelas escolas.

A Pedagogia da Alternância surge em 1935, como Maison Familiale Rural ou Casa Familiar Rural, o que, para Nosella (2012), decorre da luta por educação encampada por um grupo de agricultores e pelo Padre Granereau, pároco de uma pequena capela localizada em SerignalPéboldol, interior da França. Eles acreditavam na possibilidade de uma escolarização que atendesse às necessidades do campo e que ajudasse a ampliar os conhecimentos dos jovens que ali residiam, sem, contudo, "iludi-los" com os encantos da cidade. Guiados por tal visão, buscavam uma educação em que seria possível ao jovem estudar a partir da realidade da vida campesina. A ideia não era contrapor o ambiente rural ao urbano, mas reconhecer a dignidade do campo e compreendê-lo como produtor de cultura, de modos de vida, e não apenas como lugar de produzir alimentos.

No Brasil, a chegada da Pedagogia da Alternância se deu pelo Estado do Espírito Santo, no fim da década de 1960, sob a liderança do padre italiano da Companhia de Jesus, Humberto Pietrogrande. O desenvolvimento dessa 
pedagogia ocorre no âmbito do Movimento de Educação do Espírito Santo (MEPES), vinculado à Associação dos Amigos do Espírito Santo, que mantinha no Sul do Estado um hospital e uma creche. Conforme Nosella (2012), o MEPES é uma instituição filantrópica organizada pela sociedade civil. Com o movimento em defesa da Pedagogia de Alternância, sua tarefa foi criar e manter as Escolas Família Agrícola e o Centro de Formação e Reflexão (CFR).

Como consequência desses esforços, em 1969, foi criada a primeira unidade a usar o regime de alternância no País, denominada Escola Família Agrícola de Olivânia, situada no município de Anchieta (ES). Inicialmente, foram criadas as EFA's no Sul e, posteriormente, no Norte do Espírito Santo (Nosella, 2012). O MEPES tornou-se, assim, referência em Pedagogia da Alternância no Brasil, sendo, atualmente, o mantenedor de 18 unidades que a adotam, prestando apoio pedagógico a escolas em alternância por todo o Brasil, por meio do CFR, localizado no município de Piúma (ES).

No Espírito Santo, pedagogicamente, essas escolas guiam-se pelos parâmetros nacionais de educação, os quais lhes garantem certa autonomia em relação à organização dos conteúdos. Por exemplo, a Lei 9.394/1996 (Lei de Diretrizes e Bases da Educação Nacional - LDBEN), em seu art. 28, assim prevê:

$\mathrm{Na}$ oferta de educação básica para a população rural, os sistemas de ensino promoverão as adaptações necessárias à sua adequação às peculiaridades da vida rural e de cada região, especialmente:

I - Conteúdos curriculares e metodologias apropriadas às reais necessidades e interesses dos alunos da zona rural...

Nessa perspectiva, as Superintendências Regionais de Educação, vinculadas à SEDU, fazem $o$ acompanhamento das escolas em alternância respeitando este artigo da LDBEN. Desse modo, as unidades têm a autonomia de que necessitam para organizar todo o trabalho em alternância, de acordo com os temas geradores, com base nos quais são conduzidos os Planos de Estudo, processo no qual recebem assessoria do CFR.

A Pedagogia da Alternância, como já denota a nomenclatura, alterna períodos de aprendizagem na escola e em casa e/ou comunidade, o que, de certa forma, configura uma adaptação às condições do meio em que o aluno vive, como prevê o já citado art. 28 da LDBEN. Acontece, assim, a adaptação necessária às peculiaridades da vida rural, pois, indiretamente, considerase a grande distância entre a casa e a 
escola, realidade comum no meio rural. Por essa e outras particularidades, a Pedagogia da Alternância é, na prática, a alternativa adequada de promoção da educação e formação escolar das pessoas do campo.

De acordo com Nosella (1977, p. 8), a fórmula básica da pedagogia da alternância, como é fácil perceber, expressa um compromisso político bem preciso: rejeita a discriminação do homem e da cultura do campo, embasa o processo educativo na responsabilidade fundamental e inalienável da família e da comunidade, bem como na dialética entre teoria e prática.

Nessa via, cabe à comunidade escolar o envolvimento com a aprendizagem das crianças e jovens, no sentido de interagir e discutir sobre os aspectos do trabalho, a vivência no meio familiar e comunitária, bem como contribuir em estudos e pesquisas sobre a realidade. Isso porque a Pedagogia da Alternância busca integrar o conhecimento empírico ao cientificamente construído e/ou sistematizado na sessão escolar.

Para efetivar a indissociabilidade entre as esferas escolar e comunitária, o regime de alternância busca parcerias com os familiares e associações, de modo a garantir a interação e o monitoramento dos alunos no "Tempo Escola" e no "Tempo
Comunidade". O "Tempo Comunidade" é o período em que os alunos permanecem em seu meio sociocultural, na convivência com a família e a comunidade, envolvidos na organização e realização do processo produtivo familiar. Em razão dessa dinâmica, é imprescindível o apoio das famílias para o bom desenvolvimento dessa pedagogia. Por isso, é de suma importância à compreensão da metodologia por parte da comunidade, sob o risco de a alternância não se concretizar ou, então, ocorrer de forma precária.

Quando adotada com todas as suas ferramentas, a Pedagogia da Alternância leva à reflexão sobre as realidades específica e geral dos alunos. Por meio do trabalho em grupo, leva-os a usufruir de uma formação social guiada pela autoorganização coletiva adotada no contexto escolar. Isso se torna possível graças ao "Plano de Estudo" (PE), que, na definição de Gerke (2007, p. 124), constitui-se em um instrumento de reflexão e problematização da realidade, que norteará as demais aprendizagens e aprofundamentos necessários. O PE é realizado a partir de um tema gerador previamente acordado com a comunidade escolar e que buscará, por meio da metodologia da pesquisa, responder às necessidades locais. 
Portanto, o "Plano de Estudo" consiste em uma ferramenta que possibilita a participação dos pais e alunos na construção do currículo escolar. Por seu intermédio, os alunos, divididos em grupos e após serem motivados pelos professores, elaboram perguntas a partir de temas geradores definidos no projeto políticopedagógico da EFA's. Essas perguntas são examinadas por todos os alunos e professores, em momento denominado "Colocação em Comum”, no qual são selecionadas aquelas que melhor atendem ao estudo do tema proposto.

$\mathrm{Na}$ sequência, os alunos, sob monitoria dos professores, organizam um questionário com as perguntas selecionadas, obedecendo a critérios que facilitem a produção textual. No "Tempo Comunidade", eles buscam respostas por meio de entrevistas com os pais e/ou outros membros da comunidade. Com as respostas em mãos, esquematizam um relatório em forma de texto, produzindo uma nova ferramenta de aprendizagem, denominada "Redação Individual". No "Tempo Escola" que sucede esse período, os grupos se reúnem para produzir a "Síntese Geral" a partir das redações individuais.

Com a exposição dessa dinâmica, percebe-se a participação efetiva da comunidade na produção dos textos, pois neles estão inseridas as respostas obtidas nas entrevistas. Isso garante uma práxis curricular a partir da dialética escolacomunidade. Além disso, os alunos realizam um intensivo trabalho em grupos, o que não só fortalece o senso de atuação em equipe, como também a autonomia. $\mathrm{O}$ uso dessas ferramentas contribui para a formação social, também porque existe forte estímulo à auto-organização coletiva, já que os professores, neste contexto, adotam uma postura de monitoria, deixando a cargo dos alunos a produção do "Plano de Estudo".

Esse movimento de estudos e de formação implica processos reflexivos que envolvem produções, leituras, análises e sínteses. Os monitores elaboram suas aulas a partir do currículo "gerado" por meio do "Plano de Estudo", sendo esta, portanto, a ferramenta norteadora do currículo da escola em regime de alternância. A prática da Pedagogia da Alternância, nesse sentido, contribui para promover uma reflexão baseada na dinâmica sugerida por Freire (2005, p. 117):

simplesmente, não posso pensar pelos outros, nem para os outros. A investigação do pensar do povo não pode ser feita sem o povo, mas com ele, como sujeito de seu pensar. E seu pensar é mágico ou ingênuo, será pensando o pensar, na ação, que ele mesmo se superará. E a superação não se faz no ato de consumir ideias, mas de produzi-las e de transformálas na ação e na comunicação. 
Percebe-se, portanto, uma produção curricular coletiva, em que a escola é mediadora de processos e relações democráticas e emancipatórias, o que favorece a permanente problematização do conhecimento preconizado pelas disciplinas escolares, que produzem o "Tempo Escola" e o "Tempo Comunidade". Mostra que não apenas é necessário, mas possível promover o diálogo entre as culturas e os conhecimentos, sem dicotomizar o que se vive na escola e o que se vive na comunidade.

Em síntese, a Pedagogia de Alternância possibilita que o filho do camponês estude por uma semana, o dia todo, na escola, e, na outra semana, realize imersão na vida comunitária, onde realizará atividades teóricas e práticas com sua família e comunidade. Como construção coletiva da organização de base dos agricultores familiares, as EFA's consolidaram-se por acreditar no homem do campo e na possibilidade de promover uma educação diferenciada e alternativa, atribuindo protagonismo aos sujeitos do campo na organização e promoção da educação de seus filhos.

\section{Aspectos metodológicos}

De natureza qualitativo-descritiva, esta pesquisa busca evidenciar como as famílias dos alunos da Escola Emílio Schroeder, situada em Alto Santa Maria, comunidade pomerana de Santa Maria de Jetibá (ES), compreendem o modelo de alternância na formação de seus filhos. O estudo abarca a análise de dados primários, obtidos a partir de relato de experiência de uma professora-monitora de escolas que utilizam a Pedagogia de Alternância, incluindo a Escola Emílio Schroeder, bem como dados secundários, oriundos de pesquisa documental.

Os documentos são fichas em que foram registradas visitas a famílias, realizadas por professores da unidade escolar, prática recorrente no modelo em alternância, sendo importante canal de comunicação entre ambas as partes. Entre outros objetivos, a visita, no modelo de alternância, busca compreender a vida social, política, econômica e demais aspectos dos núcleos em que vivem os alunos, empregando, para tanto, técnicas padronizadas de coleta de dados.

As fichas analisadas nesta pesquisa são aquelas que foram aplicadas a 52 famílias em 2011 (agosto a outubro), portanto, uma década após a implantação da alternância na Escola Emílio Schroeder. Tal instrumento constitui-se em um questionário, apresentando às famílias seis perguntas: 1) Por que seu filho estuda nessa escola?; 2) A escola corresponde às 
suas expectativas?; 3) Cite, no mínimo, três vantagens de seu filho estudar em escola em alternância; 4) Cite as desvantagens de a escola atuar em alternância; 5) Em que a escola poderia ajudar mais as famílias da comunidade; 6) $\mathrm{O}$ que você gostaria que a escola ensinasse a seu filho, além do que ele já aprende?

A coleta das respostas foi feita por professores que, em duplas, visitavam, semanalmente, de duas a quatro famílias. As respostas foram registradas na própria ficha. A análise aqui realizada, entretanto, abarcou apenas quatro das seis perguntas (1 a 4, logo, todas não estruturadas) e permitiu observar possíveis mudanças entre a visão que as famílias respondentes mostraram ter sobre o modelo de alternância em relação à visão daquelas que, no início dos anos 1990, passaram a reivindicar essa filosofia na escola da comunidade, estando esta mais detalhadamente exposta na seção 5 deste artigo.

Quanto à professora-monitora cuja experiência é relatada no trabalho (seção 4), trata-se de uma integrante do corpo docente da Escola Emílio Schroeder desde 2004, tendo realizado sua pesquisa de mestrado na comunidade onde se situa a unidade escolar, na qual continua desenvolvendo pesquisa (doutorado). Atuando, ao mesmo tempo, no campo de trabalho e de pesquisa, lhe foi possível perceber a necessidade de analisar as fichas de visitas que faziam parte de sua rotina de trabalho na escola e introduzi-las nesta pesquisa com a devida anuência da escola.

\section{Experiência de uma professora- monitora na Pedagogia da Alternância}

No trabalho com a Pedagogia de Alternância, o Centro de Formação e Reflexão cumpre uma tarefa fundamental para que as EFA's possam produzir coletivamente essa filosofia educacional. É por meio do CFR que são oferecidas as formações para os professores que atuam como monitores em escolas de alternância. Vejamos o que diz uma professoramonitora a respeito dessa atividade.

Em 2004, quando iniciei minha prática de Pedagogia da Alternância na então Escola Estadual de Ensino Fundamental Fazenda Emílio Schroeder, foi possibilitado aos professores ingressar no curso de qualificação de monitores de escolas em regime de alternância. $\mathrm{O}$ curso era oferecido pelo MEPES, onde ocorre a formação inicial e continuada dos professores que atuam nas escolas situadas do Espírito Santo que se organizam a partir dessa filosofia. A identificação com a educação diferenciada oferecida pela entidade filantrópica foi imediata. Percebi, 
também, diferenças consideráveis em relação à pedagogia que até então era adotada na EEEF Fazenda Emílio Schroeder, já que, nesta unidade, a alternância é mesclada ao ensino convencional, pois não está plenamente implantada, como nas EFA's (depoimento de uma professora-monitora).

É interessante destacar que a mesma professora-monitora, pouco tempo depois dessa formação, vivenciou experiência de trabalho na EFA de São João do Garrafão, onde acompanhou e orientou didaticamente diversos projetos de pesquisa e experimentação desenvolvidos pelos alunos provenientes do meio rural. Tais projetos, em sua visão, caracterizavam-se por elevada qualidade, sendo apreciados e aprovados por órgãos oficiais, tais como as secretarias de Educação e Agricultura do município de Santa Maria de Jetibá; o Instituto Capixaba de Pesquisa, Assistência Técnica e Extensão Rural (INCAPER) e o Centro de Ciências Agrárias da Universidade Federal do Espírito Santo.

Pela adoção do regime de alternância em sua integralidade, os trabalhos dos alunos na EFA de São João do Garrafão, conforme avaliação da professoramonitora, estimulavam a reflexão sobre o quanto o campo tem a oferecer aos jovens que nele vivem em termos de oportunidades para o cultivo agroecológico em suas pequenas propriedades. Por isso, a prática com a Pedagogia da Alternância, em suas considerações, permite uma percepção do campo como lugar privilegiado, em que os jovens alunos podem viver de escolhas conscientes, compreendendo o valor do território que habitam para a sociedade.

Para atuar nessa perspectiva, o campo requer a presença de uma escola que ofereça uma educação que valorize e promova as culturas dos sujeitos campesinos. Assim, a escola contribui para problematizar o êxodo rural dos alunos como possibilidade única de vida. A escola pode contribuir para promover debates sobre as contradições da produção das existências dos sujeitos que trabalham na terra: falta de infraestrutura básica, precárias condições de trabalho por omissão do Estado na promoção de políticas públicas de financiamento $\mathrm{e}$ escoamento da produção etc.

Por outro lado, a escola pode questionar, também, os problemas das cidades: falta de saneamento básico, condições precárias de moradia e de transporte, altos índices de violência etc. Em síntese, como uma das experiências interculturais de Educação do Campo no Estado do Espírito Santo (Foerste, SchützFoerste \& Merler, 2013), a Pedagogia da 
Alternância ajuda a fortalecer debates coletivos por direitos sociais daqueles que vivem no meio rural e nas cidades.

Dimensão constituidora das bases de formação humana e um dos pontos centrais da Pedagogia da Alternância, o engajamento com a comunidade foi observado pela professora-monitora em duas oportunidades.

Durante curta experiência administrativa em 2006 na EFA de São João do Garrafão, pude trabalhar em parceria com o INCAPER, a Secretaria Municipal de Agricultura e os supermercados de Santa Maria de Jetibá. Isso favoreceu que os alunos do Curso Técnico em Agropecuária promovessem uma campanha de divulgação da batata yacon, que resultou, inclusive, na publicação de um artigo científico ${ }^{i}$. Originário dos Andes, em Santa Maria de Jetibá, o produto até então era desconhecido dos consumidores, embora fosse cultivado em suas propriedades rurais. $\mathrm{Na}$ oportunidade, foi possível verificar a satisfação dos alunos participantes, por se sentirem valorizados como produtores, divulgadores e comerciantes daquele alimento, privilégio que, desde a mecanização e divisão técnica do trabalho promovida pela Revolução Industrial, resta a trabalhadores em poucos ofícios (depoimento de uma professoramonitora).

Outra experiência foi vivenciada em 2007, durante a realização do I Seminário de Pós-Colheita de Hortaliças, também na EFA de São João do Garrafão. O evento objetivou difundir informações sobre novas tecnologias pesquisadas pelo INCAPER e teve como parceiros os mesmos órgãos públicos da experiência anterior, contando com a participação de pais, alunos, ex-alunos e membros da comunidade e adjacências. Assim como na campanha para divulgar a batata yacon, no seminário, foi possível notar a reponsabilidade social da Pedagogia da Alternância.

Em 2008, retomei os trabalhos docentes na Escola Emílio Schroeder. Senti a necessidade de refletir sobre as diferenças entre o modo como a Pedagogia da Alternância era adotada ali e a forma como ocorria na EFA de São João do Garrafão. Na Emílio Schroeder, à época e ainda hoje, há uma mescla da alternância com a metodologia convencional. Já em São João do Garrafão, a adoção desse modelo ocorre integralmente, com a prática educativa acontecendo em parceria com a comunidade e com entidades governamentais e associações. Por isso, na Emílio Schroeder, notei um trabalho mais solitário da escola, sem um vínculo tão 
estreito com a vida comunitária, embora se observe algum nível de participação das famílias. Porém, o ensino nos moldes da alternância parte do princípio de que o aluno recebe da família o apoio de que necessita para se desenvolver, tanto nos estudos realizados no "Tempo Comunidade" quanto nos períodos de aprendizados que ocorrem no espaço da escola (depoimento de uma professoramonitora).

Em outras palavras, a Pedagogia de Alternância possibilita aos alunos do meio rural uma alternativa ao sistema escolar convencional, padronizado e fortemente controlado pelo governo. Nesse sentido, a família participa da construção da história da escola, que, por sua vez, abre seu espaço para a comunidade. Por isso, a proposta em regime de alternância requer um estabelecimento que integre a família, a comunidade e a escola em todos os aspectos: cultural, espiritual, social e prático.

A alternância implica o esforço de conscientização do valor das culturas, entendidas como uma força do povo. Se a educação a ele estiver aliada, tem-se um forte instrumento de libertação, pois, conforme postula Freire (2005, p. 41), "quanto mais conscientemente faça sua história, tanto mais o povo perceberá, com lucidez, as dificuldades que tem a enfrentar, no domínio econômico, social e cultural, no processo permanente da sua libertação".

\section{Caracterização da escola e da comunidade escolar}

A EEEFM Fazenda Emílio Schroeder situa-se na Estrada de Alto Santa Maria - Garrafão, comunidade de Alto Santa Maria, a $20 \mathrm{~km}$ de distância do Centro de Santa Maria de Jetibá (ES). Funciona em dois prédios, distantes $2 \mathrm{~km}$ um do outro: um é ocupado pelas séries iniciais do Ensino Fundamental; o outro, pelas séries finais e pelo Ensino Médio. No ano letivo de 2019, a escola atendeu a 97 alunos nas séries iniciais do Ensino Fundamental, 113 nas séries finais e 37 no Ensino Médio.

A maior parte da população da comunidade rural em que a escola está instalada é constituída por descendentes de pomeranos, povo que chegou ao Espírito Santo em meados do século XIX, como descrevem Jacob (2011) e Foerste (2016a, 2016b), vindo da antiga Pomerânia. Essa região não mais existe hoje com tal denominação e suas terras atualmente estão distribuídas na Alemanha (30\%) e na Polônia (70\%).

Os descendentes de pomeranos seguem a Igreja Luterana e têm como principal atividade econômica a agricultura 
familiar, baseada na pequena propriedade, mantendo, até hoje, algumas de suas tradições. Entre elas, está a língua pomerana, que ainda predomina na sua comunicação no ambiente familiar, de modo que várias crianças chegam à escola sem saber se expressar no idioma oficial do Brasil.

Em Alto Santa Maria, as poucas opções de lazer se resumem a um campo de futebol de areia, que pertence à mesma escola; uma quadra de esportes, fruto de uma parceria entre a Prefeitura Municipal de Santa Maria de Jetibá e o Governo do Estado do Espírito Santo; festas e eventos promovidos pela escola, igreja e em caráter particular. A comunidade se destaca no município por possuir várias associações de agricultores, abrangendo, principalmente, a agricultura orgânica e ecológica.

Nesse movimento, destaca-se a Associação dos Produtores Santamarienses de Defesa da Vida, criada em 1989 com o objetivo de organizar os produtores para a comercialização de produtos orgânicos da região de Santa Maria de Jetibá em feiras livres que ocorrem na Região Metropolitana da Grande Vitória em outras cidades capixabas. Mais adiante, em 2001, também na comunidade de Alto Santa Maria e com esses mesmos objetivos, surgiu a Associação Amparo Familiar.
Esta, entretanto, tem como foco a promoção do comércio de orgânicos em nível local.

As mulheres de Alto Santa Maria também estão reunidas em associação, a qual denominaram "As mães da terra". Criada por trabalhadoras rurais em 2008, a entidade busca formas alternativas de subsistência e luta pela garantia dos direitos da mulher, da educação, do reconhecimento profissional, do resgate da cultura pomerana, engajando-se, inclusive, na organização em torno das comemorações dos 160 anos da imigração do povo pomerano no Brasil, realizadas em 2019.

Também em 2008, foi criada na comunidade a Cooperativa de Agricultores Familiares, que oferece suporte às outras associações existentes no município. Seu objetivo é a compra, de forma cooperada, de insumos agrícolas, visando ao fortalecimento da agricultura familiar pela comercialização direta para entidades governamentais, por exemplo, por meio do Programa Nacional de Alimentação Escolar.

Dada a intensa atividade de agricultura familiar na região, os moradores tinham necessidades específicas, pela própria dinâmica do trabalho no campo e por considerarem os membros da família, inclusive as crianças e 
adolescentes, como ajudadores nas tarefas de plantar e colher, uma vez que isso é o que mantém seu sustento.

Em decorrência disso, uma importante mobilização ocorreu em Alto Santa Maria em 1993, com a criação de uma associação para defender a implantação da Pedagogia de Alternância na escola da comunidade. $\mathrm{O}$ primeiro presidente desse movimento foi Daniel Plaster, sucedido por Lorival Haese e Sifrit Jastrow. Todos eles trabalharam com base em um intuito comum: trazer o regime de alternância para a escola, de modo que os laços entre a unidade escolar, a comunidade e o modo de vida campesino se tornassem cada vez mais fortes.

Todavia, antes de descrever os desdobramentos dessa mobilização, é importante salientar que a trajetória de luta dos moradores de Alto Santa Maria em relação à educação vem de mais longe. Em 1968, eles se organizaram para construir a primeira sala de aula da comunidade, designando um de seus moradores como seu primeiro professor: Emílio Schroeder, o qual veio a dar nome à escola. Quase três décadas adiante, a comunidade havia crescido e, como consequência, veio a necessidade de se promover a ampliação do ensino. Assim, em 1994, por iniciativa de 23 famílias, a Escola Emílio Schroeder foi transformada em uma unidade completa de Ensino Fundamental, passando a adotar, progressivamente, o Ensino Fundamental da $5^{\mathrm{a}}$ à $8^{\mathrm{a}}$ séries.

Em seguida, a comunidade organizou visitas a projetos de EFA's implementados no Espírito Santo pelo MEPES. Pais, lideranças comunitárias e a equipe da Escola Emílio Schroeder estudaram a Pedagogia da Alternância. Interessaram-se, de forma muito especial, pela alternância entre "Tempo Escola" e “Tempo Comunidade", com o trabalho escolar sendo desenvolvido em momentos de aula convencionais (teoria) e momentos de prática na lavoura e criação de animais de pequeno porte, visando à articulação entre a teoria e a prática, bem como a possibilidade de permanente contato do aluno com a atividade agrícola.

Todo esse envolvimento da comunidade com a escola favoreceu a adoção do novo regime na unidade. Em atendimento à sua reivindicação, a SEDU acabou por permitir a implantação do modelo da Pedagogia da Alternância na Escola Emílio Schroeder, o que ocorreu por meio da Resolução 157/2000 do Conselho Estadual de Educação do Espírito Santo, datada de 20 de setembro de 2000, publicada no Diário Oficial somente em 26 de janeiro de 2001.

O movimento de luta pela implantação da Pedagogia de Alternância 
erguido pela força da população local, posteriormente, foi denominado Associação de Pais, Alunos, Ex-alunos, Professores e Servidores da Escola Família Agrícola Fazenda Emílio Schroeder, sendo mantido até hoje. É importante registrar que, embora a escola oficialmente nunca tenha adotado a nomenclatura "Escola Família Agrícola", por seguir a orientação da SEDU para identificar-se como estadual, a comunidade, carinhosamente, se refere a ela como Familgeschaul ("escola família").

A implantação da Pedagogia da Alternância na Escola Emílio Schroeder teve forte repercussão à época. Isso porque esta foi a experiência pioneira de alternância na rede estadual de ensino no Espírito Santo. Logo surgiu uma problemática muito discutida ainda hoje: como um estabelecimento da rede pública estadual de ensino trabalha em seu projeto político-pedagógico a Pedagogia da Alternância?

$\mathrm{Na}$ prática, por um lado, era necessário ajustar a Pedagogia da Alternância às normas oficiais de educação; por outro, foram criadas alternativas de práticas pedagógicas que adequaram o projeto oficial de educação aos pressupostos da Pedagogia da Alternância adotada nas EFA's e recebidas muito positivamente pelas famílias e comunidades locais. Os Planos de Estudo, por exemplo, ferramenta que, na Pedagogia da Alternância, direciona o currículo, foram orientados de modo a contemplar os temas transversais da rede estadual.

Nesse sentido, a escola em questão esforça-se para cumprir seu papel de educar, dedicando-se ao máximo a promover a integração com as famílias, a fim de perceber as dificuldades enfrentadas por pais e alunos no dia a dia. Além disso, na medida do possível, trabalha de forma colaborativa com as famílias e comunidades, para investigar problemas e buscar saídas alternativas para as dificuldades ali encontradas. As pesquisas realizadas pela escola produzem dados que fundamentam o planejamento e oferta de cursos, palestras e debates com profissionais qualificados na escola e em outros espaços comunitários (igrejas, salões de festas, associações etc.).

É importante ressaltar que, atualmente, a Escola Emílio Schroeder recebe alunos de diversas localidades vizinhas de Alto Santa Maria, os quais também integram a comunidade escolar, ainda que geograficamente habitem espaços diferentes. Assim, o público atendido pela escola abarca um perímetro que vai além de Alto Santa Maria. Partindo disso, os dados aqui produzidos e 
analisados também não se limitam exclusivamente a esta comunidade.

Em Alto Santa Maria e adjacências, a maior parte da população, como em todo o município de Santa Maria de Jetibá, tem ascendência pomerana. O município, inclusive, é considerado o mais pomerano do Brasil, com $80 \%$ de sua população composta por descendentes desse grupo étnico, conforme já discutido em diversas pesquisas (Dettmann, 2014; Hartuwig, 2011; Schaeffer, 2012; Siller, 1999; Tressmann, 2005; Weber, 1998).

No Brasil, os imigrantes pomeranos, segundo Heinemann (2008, p. 7), foram considerados os que melhor se adaptaram ao trabalho na agricultura:

a experiência desse povo no trabalho junto à terra é milenar. Para comprovar isso, basta visitá-los no Espírito Santo, entre montanhas e vales. Com todos os percalços durante o ano: seca, chuvas fortes, frio, sol escaldante, eles abastecem grandemente outras regiões vizinhas e a capital.

É importante ressaltar que as regiões do Espírito Santo com maior produção de hortigranjeiros em sistema de policultura familiar são as de imigração pomerana. No setor de granjeiros, o município de Santa Maria de Jetibá se destaca em nível nacional como o maior produtor de ovos do Brasil. Com relação à agricultura, além de abastecer o mercado na própria região, os produtos (convencionais e orgânicos) são comercializados na Região Metropolitana da Grande Vitória, no Norte do Estado e em mercados do Rio de Janeiro, São Paulo, Minas Gerais e Bahia.

Esse destaque na produção agrícola deve-se em parte, ao fato de que, segundo Fehlberg, Menandro e Meira (2011), os pomeranos mantêm a característica de trabalhadores fortes e dedicados, já observadas na Pomerânia, de onde, em 1839, conforme Biewer (2003), saíam três quartos das batatas produzidas na Alemanha. Além disso, Jacob (1992, p. 14) sublinha que "a Pomerânia também se orgulha por ter sido, em épocas remotas, considerada o 'Celeiro Agrícola' da Europa. Época em que a sua população era bem mais nutrida e caracterizada pela sua robustez, pelo árduo trabalho, resistência e paciência".

Tamanha dedicação ao trabalho agrícola e escasso cuidado com a pele clara rende aos pomeranos alguns problemas de saúde que se evidenciam em rostos precocemente envelhecidos e marcados pelo sol. Segundo a descrição do perfil dos alunos apresentada no Projeto PolíticoPedagógico (PPP) da Escola Estadual de Ensino Fundamental e Médio Fazenda Emílio Schroeder (2014), falar de seus educandos é referir-se a crianças e adolescentes, em sua maioria, pomeranos, 
loiros, filhos de pequenos agricultores. $\mathrm{O}$ mesmo documento assim os descreve:

a terra está encravada em suas unhas, sua pele, pois participam da vida do campo, ora na brincadeira, ora para auxiliar a família na sua faina diária. Sua pele clara é marcada pelo sol, que deixa inúmeras pintinhas em seus rostos. (Escola Estadual de Ensino Fundamental e Médio Fazenda Emílio Schroeder, 2014, p. 13).

A partir dessa descrição do PPP da escola e dos autores anteriormente mencionados, é possível notar que os pomeranos têm com a terra uma relação que vai além da simples posse. Eles a cultivam e a cultuam, sem dela se dissociar, o que denota uma relação quase mítica. Bahia (2000, p. 255), aliás, pontua que "a metáfora bíblica de Canaã ... é evocada na imagem construída do imigrante que busca a liberdade e a terra", destacando ainda um conhecido provérbio entre os pomeranos: "aos primeiros, a morte. Aos segundos, a miséria. Aos terceiros, o pão". Esse provérbio representa a forma como os pomeranos narram sua relação com a terra, gradativamente construída pelo ethos do trabalhador camponês, desde os seus primórdios (Bahia, 2000).

A escolarização representa um desafio para esse povo, desde sua chegada ao Espírito Santo. Na ausência de políticas públicas de educação, as comunidades pomeranas fundaram as escolas paroquiais (Castelluber, 2014). Assim como em todo o País, em que, de norte a sul, os campesinos têm pouco acesso à escola, também entre os pomeranos pesquisas sobre o nível de escolaridade apontam para estatísticas preocupantes.

No que tange especificamente à comunidade escolar da EEEFM Fazenda Emílio Schroeder, a Tabela 1 apresenta dados coletados durante censo realizado no ano letivo de 2011, abrangendo, portanto, todos os pais de alunos da escola naquele momento.

Tabela 1 - Nível de escolaridade das famílias (2011).

\begin{tabular}{|c|c|c|c|c|c|c|c|}
\hline & \multicolumn{2}{|c|}{ Ensino Fundamental } & \multicolumn{2}{|c|}{ Ensino Médio } & \multirow{2}{*}{$\begin{array}{c}\text { Ensino } \\
\text { Superior }\end{array}$} & \multirow{2}{*}{$\begin{array}{c}\text { Sem } \\
\text { estudo }\end{array}$} & \multirow{2}{*}{$\begin{array}{c}\text { Não } \\
\text { informado }\end{array}$} \\
\hline & Incompleto & Completo & Incompleto & Completo & & & \\
\hline Pai & 84 & 1 & - & 1 & - & 1 & 12 \\
\hline Mãe & 80 & 3 & 1 & 4 & - & 2 & 13 \\
\hline Total & 164 & 4 & 1 & 5 & - & 3 & 25 \\
\hline
\end{tabular}

Fonte: elaborado a partir de censo realizado pela EEEFM Fazenda Emílio Schroeder.

Importante notar que a grande maioria dos pais havia cursado apenas até a então denominada $4^{\mathrm{a}}$ série, denotando que a escolaridade dos progenitores, em sua maioria, era menor que a dos filhos. Também verificamos uma pequena 
elevação de escolaridade entre as mães em comparação com os pais, sendo que entre eles nenhum chegou a cursar o ensino superior.

Nas entrevistas e conversas informais realizadas com os professores nos horários das visitas às famílias, era comum os pais se queixarem de que a escola oficial, à época em que eram estudantes, não atendia às necessidades do campo. Por isso, contentavam-se com a instrução mínima, com a qual aprendiam operações básicas e ler, para acompanhar os hinos nos cultos na Igreja Luterana e comercializar a produção de hortifrutigranjeiros.

A agroecologia é uma prática no processo de produção dos pomeranos e o trabalho coletivo da família faz parte da agricultura de subsistência na região de Alto Santa Maria. O terreno é acidentado, por se localizar nas montanhas capixabas. As famílias reconhecem a importância da escola em suas vidas. Corrobora essa visão a já mencionada luta coletiva pela escola, que, em um primeiro momento, ofertava apenas as séries iniciais do Ensino Fundamental em classes multisseriadas e, hoje, atende da Educação Infantil ao Ensino Médio, além do movimento pela implantação da Pedagogia da Alternância na Escola Emílio Schroeder.

A comunidade de Alto Santa Maria, como se nota, apresenta características propícias para alavancar a cultura no sentido mais amplo da palavra. A luta pela educação e a criação das diversas associações visando ao desenvolvimento coletivo evidenciam a existência do sentido de comunidade postulado por Buber (1987). Assim, os indivíduos convivem motivados por laços comuns, com relações por meio do diálogo, características que, conforme o filósofo, ainda estão presentes em algumas sociedades atuais, não necessariamente localizadas em ambientes rurais, embora o meio rural seja o local onde elas mais são visíveis.

Advoga Buber (1987) que em uma comunidade autêntica não deve haver exploração, mas o esforço pelo bem da coletividade. Nessa perspectiva, os pomeranos se inserem entre as comunidades tradicionais, sobrevivendo, convivendo e se reinventando diariamente, em um esforço de cuidar do viver coletivo (Koeler, 2018). Nesse viver coletivo, a comunidade de Alto Santa Maria compartilha sua história, reproduzindo e compartilhando sua cultura, seu modo de vida, sua tradição pomerana, sendo alvo de interesse de pesquisadores da educação e da cultura.

Vale destacar, nesse sentido, a iniciativa da professora Marineuza Plaster Waiandt, que, ao transformar uma antiga casa tipicamente pomerana em "casa 
memorial", torna-se, além de guardiã da cultura de seu povo, alvo de pesquisa de tese de doutoramento de um dos autores deste trabalho, cujo objetivo fundamental é identificar as contribuições de tal iniciativa para o fortalecimento da memória coletiva do povo tradicional pomerano.

Acrescentamos que, atualmente, há na comunidade de Alto Santa Maria discussões sobre a preparação dos jovens para ingressar nos mais diversos cursos de nível superior. Entretanto, nos níveis mais elementares, ressaltamos que as demandas para uma educação plurilíngue entre os pomeranos é crescente, para manter viva sua língua materna.

A Escola Fazenda Emílio Schroeder dialoga com essa realidade, utilizando-se de ferramentas pedagógicas próprias da Pedagogia da Alternância. Nesse sentido, as visitas às famílias configuram-se como momentos de imersão importantes para a equipe escolar, que busca, por esse meio, estabelecer um canal de comunicação com atores fundamentais para o bom funcionamento do regime de alternância.

Até 2017, três horas da carga horária semanal de cada docente eram destinadas a essa atividade. Semanalmente, os professores, em duplas, visitavam de duas a quatro famílias, conforme a distância a ser percorrida. Cada visita era registrada e assinada em ficha específica, com itens direcionados de acordo com a necessidade da escola em cada período. As fichas que analisamos neste trabalho foram usadas em visitas com objetivo específico de levantar dados para a implementação do Ensino Médio na escola, consultando a comunidade, inclusive, se ela ocorreria no modelo de alternância.

Apesar da relevância da atividade, para os professores, essas visitas acarretavam transtornos de ordem técnica. $\mathrm{O}$ primeiro refere-se ao fato de que a motocicleta é o veículo principal de locomoção na região, impedindo visitas em períodos de chuvas, que são frequentes. Nessas ocasiões, por questões de segurança, os docentes dedicavam-se a realizar outras atividades, em vez de se aventurar em estradas ainda não asfaltadas. A combinação moto mais estradas precárias representa riscos de acidentes, sobretudo para os condutores mais inexperientes. Por fim, outro empecilho era o gasto com combustível, custeado pelos próprios docentes, sendo esta uma das condições para o professor assumir aulas na Escola Emílio Schroeder.

Apesar de todos esses desafios, as visitas ocorreram até 2017, quando o Governo do Estado do Espírito Santo decidiu pelo corte de verbas, obrigando a escola a cessar essa atividade. Atualmente, por reconhecer a relevância desse canal de 
comunicação com as famílias, o corpo gestor da unidade e a Superintendência Regional de Educação estão em processo de negociação com o Governo do Estado para a volta dos recursos.

\section{A Pedagogia da Alternância na visão das famílias}

Como sublinhado na seção anterior, as visitas realizadas até 2017 pela Escola Emílio Schroeder configuravam-se como canal de comunicação entre família e escola, sendo formalizadas por registro em fichas específicas, com itens formulados conforme as informações das quais a escola necessitava em cada período.

Com o objetivo de discutir o sentido da Pedagogia da Alternância na comunidade escolar da unidade em questão, nesta seção, foram analisadas as respostas dadas a apenas quatro itens de uma versão do instrumento usada com 52 famílias no segundo semestre de 2011 portanto, uma década após ali ser implantada a Pedagogia da Alternância. Essa ficha abordava com as famílias a implantação do ensino médio na mesma unidade.

Os itens avaliados questionavam sobre motivações, nível de satisfação, vantagens e desvantagens observadas pelas famílias para matricular os filhos na escola em regime de alternância. Os resultados obtidos em cada um deles encontram-se nas Tabelas 2 a 5. Uma vez que dois itens se caracterizavam como não estruturados e admitiam mais de uma resposta, o número total das respostas obtidas nas Tabelas $4 \mathrm{e}$ 5 não corresponde ao total de famílias entrevistadas (52).

Tabela 2 - Motivos pelos quais filhos estudam na EEEFM Fazenda Emílio Schroeder.

\begin{tabular}{lcc}
\hline Resposta & Quantidade & Percentual \\
\hline Por ser a mais perto de casa & 36 & $69 \%$ \\
Por causa da Pedagogia da Alternância & 35 & $67 \%$ \\
Por ser a única possibilidade de estudo & 05 & $9 \%$ \\
Outro (obrigação) & 05 & $9 \%$ \\
\hline
\end{tabular}

Fonte: elaborada pelos autores a partir das fichas de registro de visitas fornecidas pela EEEFM Fazenda Emílio Schroeder.

Tabela 3 - Atendimento das expectativas das famílias.

\begin{tabular}{ccc}
\hline Resposta & Quantidade & Percentual \\
\hline Satisfeitos & 45 & $86 \%$ \\
Insatisfeitos & 06 & $11 \%$ \\
\hline
\end{tabular}

Fonte: elaborada pelos autores a partir das fichas de registro de visitas fornecidas pela EEEFM Fazenda Emílio Schroeder. 
Tabela 4 - Vantagens de o filho estudar em regime de alternância.

\begin{tabular}{ccc}
\hline Resposta & Quantidade & Percentual \\
\hline Gosta das aulas práticas & 03 & $5,7 \%$ \\
Gosta do sistema & 01 & $1,9 \%$ \\
Possibilidade de conciliar trabalho e escola & 01 & $1,9 \%$ \\
Aprender na escola e aplicar em casa & 09 & $17,3 \%$ \\
Favorece o trabalho em casa na alternância & 35 & $67,3 \%$
\end{tabular}

Fonte: elaborada pelos autores a partir das fichas de registro de visitas fornecidas pela EEEFM Fazenda Emílio Schroeder.

Tabela 5 - Desvantagens do regime de alternância.

\begin{tabular}{ccc}
\hline Resposta & Quantidade & Percentual \\
\hline [Filho fica] Muito tempo ausente de casa & 01 & $1,9 \%$ \\
Falta retorno das atividades para a família & 01 & $1,9 \%$ \\
Merenda não é boa & 02 & $3,8 \%$ \\
Não opinaram e está bom & 46 & $88,4 \%$ \\
Dificuldade em realizar as atividades & 01 & $1,9 \%$ \\
[Filho] Assiste muita TV na sessão em casa & 01 & $1,9 \%$ \\
Falta de estrutura física da escola & 01 & $1,9 \%$ \\
Muito material para carregar & 01 & $1,9 \%$
\end{tabular}

Fonte: elaborada pelos autores a partir das fichas de registro de visitas fornecidas pela EEEFM Fazenda Emílio Schroeder.

De acordo com a Tabela 2, a maioria das famílias respondeu que seus filhos estudavam na Escola Emílio Schroeder por esta ser a unidade mais próxima de suas casas e pelo trabalho realizado em alternância. Sobre a segunda motivação, as respostas parecem mostrar um contrassenso, pois, ao listarem as vantagens da Pedagogia da Alternância, 35 deles apontaram o favorecimento do trabalho na sessão em que o filho está em casa.

A alternância, conforme descrito, possibilita que, por uma semana, o aluno estude na escola o dia todo e, na semana seguinte, dê continuidade aos estudos em casa, com sua família e comunidade. No entanto, dada a realidade socioeconômica e cultural da comunidade de Alto Santa Maria e arredores, é possível que, na semana em que está com a família, em uma tentativa de compensar sua ausência no período anterior, o aluno, voluntariamente, venha a se dedicar muito mais às atividades agrícolas. Nessa dinâmica, a alternância de lócus de estudo acaba ficando comprometida em seus resultados e propósitos.

Isso, provavelmente, decorre de que, na cultura pomerana, é comum que crianças e adolescentes desempenhem papel fundamental na organização econômica familiar. Por isso, esses atores, aos olhos de suas famílias e aos seus próprios olhos, são vistos como indispensáveis ao desenvolvimento de 
pequenas tarefas na propriedade de agricultura familiar, o que se evidenciou nas respostas obtidas.

Esses aspectos contribuem para posicionar a educação em um plano menos importante. As respostas da Tabela 4 corroboram esse pensamento. Nela, nota-se que os pais destacam como principal vantagem da escola em alternância o favorecimento do trabalho, e não propriamente o modo como a educação se processa.

Frente a essa questão, compete à escola o papel de direcionar o processo de ensino-aprendizagem aos alunos, de modo a lhes garantir uma educação de qualidade na semana em que estão no espaço da unidade, tentando não interferir na dinâmica das atividades econômicas às quais a família se dedica. Acrescenta-se o fato de que a Escola Emílio Schroeder também não conta com a necessária autonomia para por em prática todas as ferramentas do regime de alternância, o que se dá em função de que, sendo ela vinculada à rede estadual de ensino, está sujeita a seguir o currículo padronizado por esta estabelecido.

Na Tabela 3, um número considerável de pais se declarou satisfeito com o trabalho realizado na escola, o que, de certa forma, se confirma nas respostas apresentadas na Tabela 5, em que poucas desvantagens foram apontadas. Além disso, entre as que foram citadas, uma única, relacionada à ausência de retorno sobre as atividades às famílias dos estudantes, refere-se, efetivamente, à Pedagogia da Alternância.

Adicionalmente, a Tabela 5 evidencia que aproximadamente $90 \%$ dos pais preferiram não opinar, bastando-lhes um vago “está bom”. Esses dados chamam a atenção para a passividade dos pais, nos anos recentes, em relação à pedagogia adotada pela escola. Podem indicar que o sentido da Pedagogia da Alternância na vida dos pais e alunos vinculados à Escola Emílio Schroeder talvez não seja tão significativo quanto foi para as famílias que lutaram por esse modelo de ensino desde o início dos anos 1990, desejo que somente foi atendido em 2001, ocasião em que a alternância foi instituída nas séries finais do Ensino Fundamental nessa unidade.

A proposta de escola em regime de alternância, como mencionado anteriormente, surgiu para suprir a necessidade de uma formação voltada ao homem do campo. Para efetivá-la, esse modelo de escola deve ocupar-se de integrar a escola, a família e a comunidade em todos os aspectos: cultural, espiritual, social e prático. Assim, é fundamental, ainda, a realização de ações de maior 
aproximação entre família e escola, a fim de superar esses obstáculos que se interpõem aos profissionais da escola (professores e outros funcionários) e ao trio gestor (diretor, coordenador e pedagogos) para a efetivação plena da Pedagogia da Alternância.

\section{Considerações finais}

A Pedagogia da Alternância, por meio de instrumentos pedagógicos específicos, como o "Plano de Estudo", "Caderno da Realidade" e visita às famílias, constitui-se como trabalho colaborativo que articula comunidade e escola, para promover a formação humana integral e a profissionalização, sendo alternativa para a construção coletiva da Educação do Campo.

A prática da parceria, conforme discute Foerste (2005), favorece o diálogo colaborativo entre sujeitos e instituições que tenham interesses e compromissos partilhados. A integração entre a escola e a família é uma dimensão articuladora da Pedagogia da Alternância e fortalece a formação humana no contexto em que vivem os sujeitos.

A comunidade luta por direitos sociais coletivos, como é o caso da educação. Cabe ao Estado garantir a oferta de escolas e, desse modo, favorecer a formação e profissionalização dos educandos no campo e nas cidades. Assim, as comunidades locais, em suas organizações de base, problematizam a omissão do poder público ou seu controle sobre a escolarização. A parceria entre comunidade e escola fortalece a educação pública como direito do povo e dever do Estado.

Em Alto Santa Maria, em especial, um dos fatores que contribuem para a Pedagogia da Alternância se desenvolver em um nível aquém do que poderia ser alcançado talvez seja, fazendo uma alusão à expressão freireana, o excessivo "pensar do povo para o trabalho". Esse pensar é observado tanto nas famílias quanto nos próprios alunos. Os períodos em que os alunos permanecem com suas famílias também devem ser dedicados aos estudos. Porém, eles acabam mais se dedicando ao trabalho na agricultura, como tentativa de compensar sua ausência na semana anterior, quando estavam integralmente na escola.

Nessa dinâmica cultural, para a família, a escola é preterida em relação ao trabalho, dificultando a realização plena da Pedagogia da Alternância. Diante disso, a escola se vê impelida a sistematizar a formação dos alunos sem interferir na economia familiar. Por outro lado, a própria rede estadual de ensino não consegue delegar à escola a autonomia de 
que esta necessita para implantar todas as ferramentas da Alternância, acarretando desencontros em que o aluno parece ser o principal prejudicado.

Os valores, as normas, os modelos de aprendizagem, as atitudes do corpo docente, as expectativas, a participação de pais e alunos, a comunicação entre família, escola e comunidade são elementos determinantes na direção do processo de ensino em alternância e na projeção dos alunos na sociedade. No contexto apresentado, fica evidenciado que é preciso que a comunidade desperte de sua passiva comodidade, envolvendo-se no desafio do desenvolvimento educativo da Escola Emílio Schroeder, para o "pensar para a superação" na perspectiva freireana.

\section{Referências}

Bahia, J. (2000). "O tiro da bruxa": identidade, magia e religião entre camponeses pomeranos do Estado do Espírito Santo (Tese de Doutorado). Universidade Federal do Rio de Janeiro, Rio de Janeiro.

Biewer, L. (2003). História da Pomerânia [Textos de discussão do Curso sobre História da Pomerânia]. Recuperado de http://grosstuchen.cwsurf.de/GeschichtePo $\underline{\text { mmerns.html }}$

Buber, M. (1987). Sobre comunidade. São Paulo: Perspectiva.

Castelluber, A. (2014). Ensino primário e matemática dos imigrantes e docentes germânicos bem Santa Leopoldina,
Espírito Santo - Brasil (1857-1907) (Tese de Doutorado). Universidade Federal do Espírito Santo, Vitória.

Dettmann, J. M. (2014). Práticas e saberes da professora pomerana: um estudo sobre interculturalidade (Dissertação de Mestrado). Universidade Federal do Espírito Santo, Vitória.

Fehlberg, J., Menandro, P., \& Meira, R. (2011). Terra, família e trabalho entre os descendentes de pomeranos do Espírito Santo. Barbarói - Unisc. Impresso, 34, 80100.

Escola Estadual de Ensino Fundamental e Médio Fazenda Emílio Schroeder. (2014). Projeto Político-Pedagógico [Documento institucional]. Santa Maria de Jetibá, ES, Brasil.

Foerste, E. (2005). Parceria na formação de professores. São Paulo: Cortez.

Foerste, E. (2016a). Por uma articulação nacional do povo tradicional pomerano no Brasil. In Seibel, I., Foerste, E., Ullrich, H. F., Jacob, J. K., \& Heinemann, J. C. (Orgs.). O povo pomerano no Brasil (pp. 58-69). Santa Cruz do Sul: Edunisc.

Foerste, E. (2016b). Língua pomerana na atualidade: um diálogo sobre patrimônio cultural do povo tradicional pomerano. In Seibel, I., Foerste, E., Ullrich, H. F., Jacob, J. K., \& Heinemann, J. C. (Orgs.). O povo pomerano no Brasil (pp. 70-85). Santa Cruz do Sul: Edunisc.

Foerste, E., Schütz-Foerste, G. M., \& Merler, A. (2013). Educação do campo: diálogos interculturais em terras "capixabas". Vitória: Edufes.

Freire, P. (2005). Pedagogia do oprimido. (46a ed.). São Paulo: Paz e Terra.

Gerke, J. (2007). Saberes e formação de professores na pedagogia da Alternância 
(Dissertação de Mestrado). Universidade Federal do Espírito Santo, Vitória.

Hartuwig, A. V. G. (2011). Professores(as) Pomeranos(as): um estudo de caso sobre o Programa de Educação Escolar Pomerana - Proepo - desenvolvido em Santa Maria de Jetibá/ES (Dissertação de Mestrado). Universidade Federal do Espírito Santo, Vitória.

Heinemann, J. C. (2008). Bons soldados e excelentes agricultores. IHUonline: Revista do Instituto Humanista Unisinos, (271). Recuperado de http://www.ihuonline.unisinos.br/edicao/27 $\underline{1}$

Jacob, J. K. (1992). A imigração e aspectos da cultura pomerana no Espírito Santo (Vol. 3, Coleção Memórias). Vitória.

Jacob, J. K. (2011). Cidades irmãs pomeranas: Vila Pavão (ES) e Espigão do Oeste (RO). Nova Venécia: Gráfica Cricaré.

Koeler, E. (2018). Uma professora pomerana e sua comunidade: lutas coletivas pelo direito à educação. Curitiba: Appris.

Lei n. 9.394, de 20 de dezembro de 1996. (1996, 23 de dezembro). Estabelece as diretrizes e bases da educação nacional. Recuperado de http://www.planalto.gov.br/ccivil_03/leis/1 9394.htm

Nosella, P. (2012). Origens da Pedagogia da Alternância no Brasil. Vitória: Edufes.

Nosella, P. (1977). Uma nova educação para o meio rural (Dissertação de Mestrado). Pontifícia Universidade Católica de São Paulo, São Paulo.

Schaeffer, S. C. B. (2012). Descrição fonética e fonológica do pomerano falado no Espírito Santo (Dissertação de
Mestrado). Universidade Federal do Espírito Santo, Vitória.

Siller, R. R. (1999). A constituição da subjetividade no cotidiano da Educação Infantil (Dissertação de Mestrado). Universidade Federal do Espírito Santo, Vitória.

Tressmann, I. (2005). Da sala de estar à sala de baile: estudo etnolinguístico de comunidades camponesas pomeranas do Estado do Espírito Santo (Tese de Doutorado). Universidade Federal do Rio de Janeiro, Rio de Janeiro.

Weber, M. G. (1998). A escolarização entre descendentes pomeranos em Domingos Martins (Dissertação de mestrado). Universidade Federal do Espírito Santo, Vitória.

\footnotetext{
${ }^{\mathrm{i}}$ Ver Angeletti. M., Válter, C., Woelffel, A., \& Gonçalves, H. V. C. (2007). Estratégia de trabalho participativo para marketing do yacon (Smallanthus sonchifolius Poep. \& Endl.) no comércio de Santa Maria de Jetibá-ES. Revista Brasileira de Agroecologia, 2(2), 285-289.
}

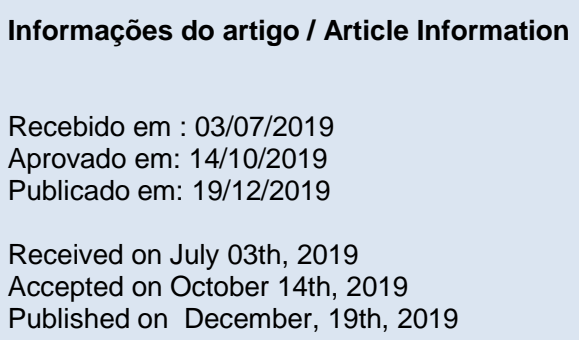

Contribuições no artigo: Os autores foram os responsáveis por todas as etapas e resultados da pesquisa, a saber: elaboração, análise e interpretação dos dados; escrita e revisão do conteúdo do manuscrito e; aprovação da versão final publicada.

Author Contributions: The author were responsible for the designing, delineating, analyzing and interpreting the data, production of the manuscript, critical revision of the content and approval of the final version published. 
Koeler, E., Foerste, E., \& Merler, A. (2019). Pedagogia da Alternância em comunidade pomerana de Santa Maria de Jetibá, Espirito Santo, Brasil...

Conflitos de interesse: Os autores declararam não haver nenhum conflito de interesse referente a este artigo.

Conflict of Interest: None reported.

\section{Orcid}

Edineia Koeler

(iD) http://orcid.org/0000-0001-7202-937X

Erineu Foerste

(iD) http://orcid.org/0000-0003-2846-0298

Alberto Merler

(iD) http://orcid.org/0000-0003-1148-2458

\section{Como citar este artigo / How to cite this article}

APA

Koeler, E., Foerste, E., \& Merler, A. (2019). Pedagogia da Alternância em comunidade pomerana de Santa Maria de Jetibá, Espírito Santo, Brasil. Rev. Bras. Educ. Camp., 4, e7129. DOI: http://dx.doi.org/10.20873/uft.rbec.e7129

ABNT

KOELER, E.; FOERSTE, E.; MERLER, A. Pedagogia da Alternância em comunidade pomerana de Santa Maria de Jetibá, Espírito Santo, Brasil. Rev. Bras. Educ. Camp., Tocantinópolis, v. 4, e7129, 2019. DOI: http://dx.doi.org/10.20873/uft.rbec.e7129 